\title{
If looks could kill...
}

A withering glance can change the dynamic of a conversation, but imagine just such a glance having the capability to frighten or stun another. Astroscopus (Latin "star seer") can do just that. The northern stargazer lives off the east coast of North America and has evolved extraordinary and shocking uses for its extraocular muscles.

Electric fish are found in at least five orders, including Torpediniformes (electrogenic rays and skates) Gymnotiformes (electric eel and others), Siluriformes (electric catfish), Osteoglossiformes (knifefishes) and Perciformes. Perciformes has but one, albeit interesting, creature to contribute to this strange ménage.

Most electric fish generate their charge from electroplaxes, which are collections of modified, stacked, and flattened muscle cells with a nerve leading to one side of this complex. The muscle cells are polarised in the same direction and generate their charge through the serial stacking and summation of these cells. They function more like a capacitor than a battery. With nervous stimulus, an electric discharge of these muscles cells can be generated. Some, such as the electric eel (Electorphorus), can generate up to $500 \mathrm{~V}$, capable of stunning, if not killing most fish it contacts. Such a discharge can render a human unconscious or dead.

The electric organ of $A$ guttatus is not as powerful as that of Electrophorus but is composed of portions of four extraocular muscles including the analogue for the superior, medial, and temporal recti as well as the superior oblique. The larval stage of this animal hatches from an egg deposited on the sea floor. The electric organ begins to develop when the larva is $12-15 \mathrm{~mm}$ long. At this stage the outer cells of these muscles begin to change into larger cells with multiple nuclei until these cells become six times the size of the normal extraocular muscle cells. These four muscles mentioned above contribute their outer layers to form a syncytium distinct from the extraocular muscles. The electric

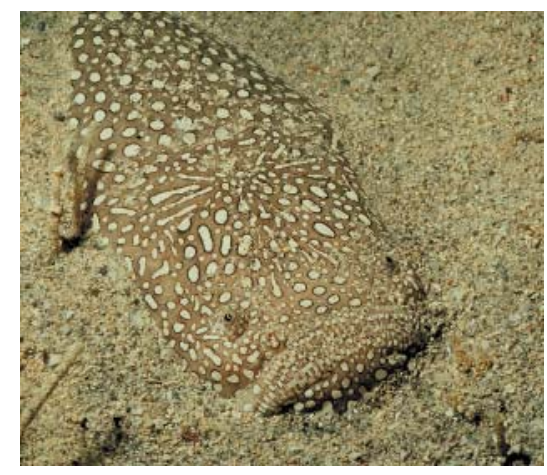

Being buried up to its eyes in sand may mean that the eyes must be proptosed above the body plane in order for the fish to see, and Astroscopus must be able to do this since it is entirely a visual predator. The fish has an opercular cavity behind the eye that can be filled with fluid causing proptosis, raising the eyes above the level of the sand.

The fish will then wait quietly and watch until a small prey species approaches. It has at least one mechanism of attracting small fish if necessary. Astroscopus has unique gill slits that discharge sea water that has passed over the gills. The water exits adjacent to the pectoral fin causing the sand just above the discharge to dance as if there were a small creature there. Potential prey fish will come to investigate. Some closely related fish have lingual lures, meaning that they have appendages extending from their tongue that resemble wriggling worms bringing prey species directly to the mouth to investigate, but Astroscopus does not have such accoutrement.

None the less, once dinner is close, Astroscopus has another amazing ocular trick. Depending upon which side the prey species approaches, Astroscopus will rotate the contralateral eye in a semicircle a few times to further tease the prey into thinking there is small burrowing organism there. This curiosity attracts the prey to cross the body of the fish towards the moving eye. Once the prey is within range, Astroscopus will lunge upward and literally suck the prey into its rather generous mouth as it creates a vacuum by opening its mouth. The electric organ has been shown to discharge simultaneously and it may have some role in confusing the prey, but does not have enough current to kill. Nevertheless, the discharge does seem to be part of the capture process.

Now, if looks could only kill.

For such a lifestyle, even the nostrils must be modified so that the fish can breathe through them while buried. The narial passages open on the dorsal surface, connect to the pharynx, and contain flaps and fimbrae to filter sand and prevent regurgitation. 